\title{
Octyl Gallate as an Intervention Catalyst to Augment Antifungal Efficacy of Caspofungin
}

\author{
Jong H. Kim *, Kathleen L. Chan and Luisa W. Cheng
}

Foodborne Toxin Detection and Prevention Research Unit, Western Regional Research Center, USDA-ARS, 800 Buchanan St., Albany, CA 94710, USA; kathy.chan@ars.usda.gov (K.L.C.); luisa.cheng@ars.usda.gov (L.W.C.)

* Correspondence: jongheon.kim@ars.usda.gov; Tel.: +1-510-559-5841

Received: 1 May 2018; Accepted: 18 May 2018; Published: 23 May 2018

\begin{abstract}
Filamentous fungi such as Aspergillus spp. are opportunistic pathogens, which cause highly invasive infections, especially in immunocompromised individuals. Control of such fungal pathogens is increasingly problematic due to the small number of effective drugs available for treatment. Moreover, the increased incidence of fungal resistance to antifungal agents makes this problem a global human health issue. The cell wall integrity system of fungi is the target of antimycotic drugs echinocandins, such as caspofungin (CAS). However, echinocandins cannot completely inhibit the growth of filamentous fungal pathogens, which results in survival/escape of fungi during treatment. Chemosensitization was developed as an alternative intervention strategy, where co-application of CAS with the intervention catalyst octyl gallate (OG; chemosensitizer) greatly enhanced CAS efficacy, thus achieved $\geq 99.9 \%$ elimination of filamentous fungi in vitro. Based on hypersensitive responses of Aspergillus antioxidant mutants to OG, it is hypothesized that, besides destabilizing cell wall integrity, the redox-active characteristic of OG may further debilitate the fungal antioxidant system.
\end{abstract}

Keywords: antioxidant system; cell wall integrity; chemosensitization; end point; fungi; small molecule

\section{Introduction}

Fungal infectious diseases, such as candidiasis, cryptococcosis or invasive aspergillosis caused by Candida, Cryptococcus or Aspergillus, respectively, are serious human health issues, since effective drugs, especially those for eliminating resistant pathogens, are often very limited ([1] and the references therein). Therefore, there is continuous need to improve the efficacy of current antifungal drugs or to discover/develop new intervention strategies. The cell wall integrity system of fungal pathogens could serve as an effective target of antimycotic drugs [2]. Genome and functional studies revealed that many genes in the cell wall integrity system of fungi are well conserved [3,4]. Caspofungin (CAS; Figure 1), like other echinocandins including micafungin and anidulafungin, is an antifungal lipopeptide drug. CAS is in clinical use due to its good solubility, antifungal spectrum and pharmacokinetic properties. CAS inhibits the activity of $\beta-1,3-\mathrm{D}$-glucan synthase in the fungal cell wall integrity system, thus disrupting the synthesis of the cell wall component $\beta-1,3$-D-glucan ([5] and the references therein). Echinocandins further lyse actively-growing hyphal tips during filamentous fungal growth [5]. However, despite their utility, echinocandins generally cannot achieve complete inhibition of the growth of filamentous fungi [6], which results in pathogen survival during treatment. 
a

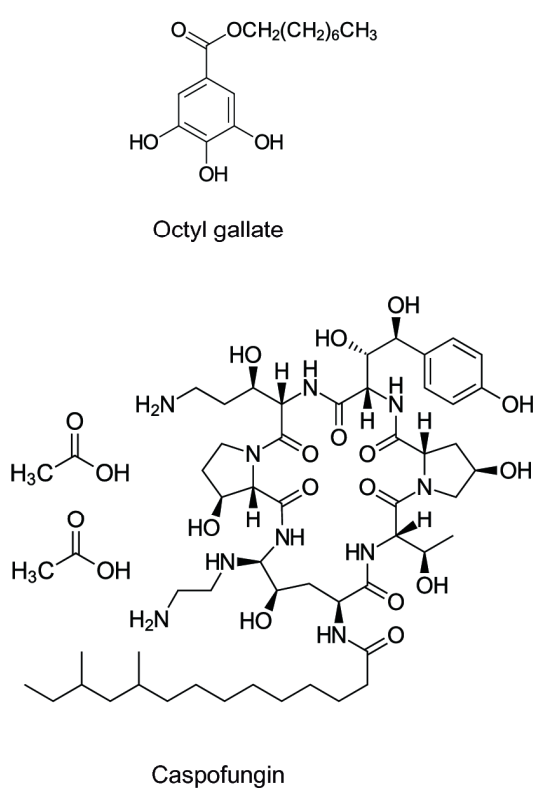

b

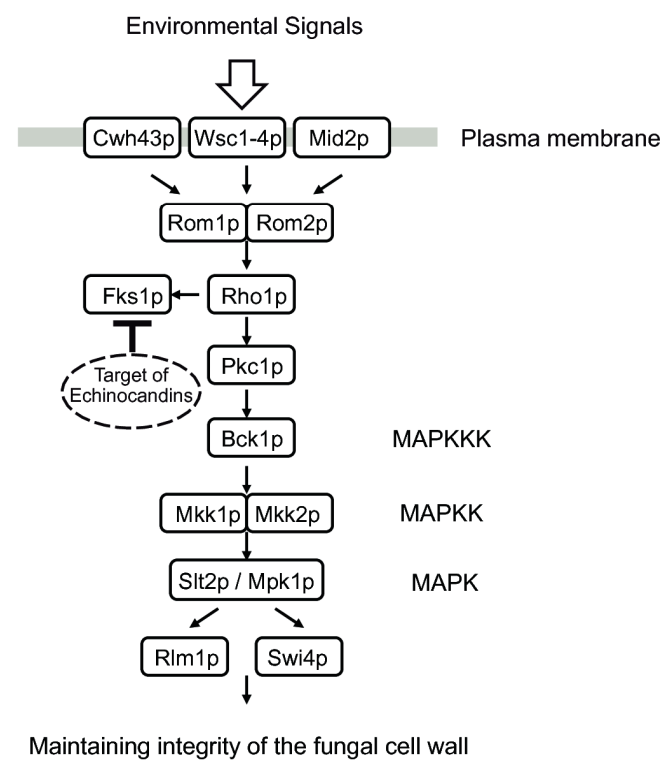

Figure 1. (a) Structures of octyl gallate (OG) and caspofungin (CAS); (b) signal transduction pathway of fungi for maintaining cell wall integrity, viz. sensing the status of the cell wall during growth and/or protecting the cell from environmental cues, such as external osmotic fluctuation (see $[4,7]$ and the references therein). See Table S1 for the functions of proteins in the pathway, except: Rom1p, GDP/GTP exchange protein for Rho1p; Cwh43p, putative sensor/transporter protein involved in cell wall biogenesis; Rho1p, GTP-binding protein, which regulates protein kinase C (Pkc1p) and the cell wall synthesizing enzyme $\beta-1,3$-D-glucan synthase (Fks1p; target of echinocandins).

Antifungal chemosensitization is an intervention strategy, where co-application of a certain natural or synthetic compound, viz. chemosensitizer (intervention catalyst), with a commercial drug greatly enhances the efficacy of the co-applied drug [8]. The key advantage of chemosensitization is that, in contrast to combination therapy, which is a co-application of two or more commercial antimycotic drugs, a chemosensitizer itself does not have to possess a high degree of antifungal potency. However, chemosensitization not only enhances the antifungal efficacy of the co-applied drug, but also mitigates pathogen resistance to conventional drugs [8]. Therefore, chemosensitization-based intervention could complement current antifungal practices, such as combination therapy.

As a proof of concept, the effectiveness of antifungal chemosensitization (CAS + octyl gallate (OG; octyl 3,4,5-trihydroxybenzoic acid)) was investigated in the species of Aspergillus and Penicillium in this study (Table 1). Test strains belong to clinical and foodborne fungal pathogens, including environmental fungal contaminants. OG, an alkyl derivative of the natural product gallic acid (Figure 1), was investigated as a potent chemosensitizer (intervention catalyst) to enhance the efficacy of cell wall-disrupting drug CAS. We recently determined that OG functioned as a safer, more effective preservative for consumer products [9]. 
Table 1. Filamentous fungal strains used in this study.

\begin{tabular}{|c|c|c|}
\hline Aspergillus Strains & Strain Characteristics & Source \\
\hline A. fumigatus AF293 & $\begin{array}{l}\text { Human pathogen (aspergillosis), parental strain, reference clinical } \\
\text { strain used for genome sequencing }\end{array}$ & [10] \\
\hline A. fumigatus sakA $\triangle$ & $\begin{array}{c}\text { Mitogen-activated protein kinase (MAPK) gene deletion mutant } \\
\text { derived from AF293 }\end{array}$ & [10] \\
\hline A. fumigatus mpkCD & MAPK gene deletion mutant derived from AF293 & [11] \\
\hline A. flavus 3357 & $\begin{array}{l}\text { Toxigenic (aflatoxin-producing), human pathogen (aspergillosis), } \\
\text { reference strain for genome sequencing }\end{array}$ & NRRL $^{1}$ \\
\hline A. flavus 4212 & Toxigenic (aflatoxin-producing), human pathogen (aspergillosis) & NRRL \\
\hline A. parasiticus 2999 & Toxigenic (aflatoxin-producing) & NRRL \\
\hline A. parasiticus 5862 & Toxigenic (aflatoxin-producing) & NRRL \\
\hline Penicillium Strains & Strain Characteristics & Source \\
\hline P. expansum $\mathrm{W} 1$ & Toxigenic (patulin-producing; parental strain) & [12] \\
\hline P. expansum FR2 & Fludioxonil resistant mutant derived from P. expansum W1 & [12] \\
\hline P. expansum $\mathrm{W} 2$ & Toxigenic (patulin-producing; parental strain) & [12] \\
\hline P. expansum FR3 & Fludioxonil resistant mutant derived from P. expansum W2 & [12] \\
\hline P. glabrum 766 & Environmental contaminant & NRRL \\
\hline P. chrysogenum 824 & Fleming's penicillin-producing strain & NRRL \\
\hline P. griseofulvum 2159 & Environmental contaminant & NRRL \\
\hline P. italicum 983 & Environmental contaminant & NRRL \\
\hline
\end{tabular}

\section{Materials and Methods}

\subsection{Chemicals}

All chemicals including antifungal compounds (caspofungin (CAS), octyl gallate (OG)) and culture media were procured from Sigma Co. (St. Louis, MO, USA). CAS and OG were dissolved in dimethylsulfoxide (DMSO; absolute DMSO amount: $<2 \%$ in media) before incorporation into culture media. Throughout this study, control plates (no treatment) contained DMSO at levels equivalent to that of cohorts receiving antifungal agents, within the same set of experiments.

\subsection{Antifungal Bioassay: Saccharomyces cerevisiae}

Susceptibility of the model yeast S. cerevisiae (See Table S1) was tested according to the protocol outlined by European Committee on Antimicrobial Susceptibility Testing (EUCAST) for yeasts [13]. Quantitative 96-well microtiter plate broth-dilution assays were performed in triplicate in liquid synthetic glucose (SG; yeast nitrogen base without amino acids $0.67 \%$, glucose $2 \%$ with appropriate supplements: uracil $0.02 \mathrm{mg} / \mathrm{mL}$, amino acids $0.03 \mathrm{mg} / \mathrm{mL}$ ) medium, where the minimum inhibitory concentration (MIC; lowest concentration of compound showing no visible fungal growth in microtiter wells $\left(200 \mu \mathrm{L}\right.$ per well)) was assessed after $24 \mathrm{~h}$ at $30^{\circ} \mathrm{C}$. Minimum fungicidal concentration (MFC; lowest concentration of compound showing $\geq 99.9 \%$ death of fungal cells inoculated, viz. achievement of $\geq 3 \log$ fungal elimination) was determined after completion of MIC assays by spreading entire volumes of microtiter wells $(200 \mu \mathrm{L})$ onto individual yeast peptone dextrose (YPD; Bacto yeast extract $1 \%$, Bacto peptone $2 \%$, glucose $2 \%$ ) recovery plates. Colony-forming units were counted after additional incubation of plates for $48 \mathrm{~h}$ at $30^{\circ} \mathrm{C}$. 


\subsection{Antifungal Bioassay: Filamentous Fungi}

To determine the level of compound interactions, namely the chemosensitizing activity of OG to CAS, in filamentous fungi (Table 1), triplicate checkerboard bioassays $\left(4 \times 10^{3}-5 \times 10^{4} \mathrm{CFU} / \mathrm{mL}\right)$ were performed in 96 -well microtiter plates at 28 or $35^{\circ} \mathrm{C}$, depending on the types of strains, using a broth microdilution method in RPMI 1640 medium (Sigma Co., St. Louis, MO, USA) according to the protocol described by the Clinical and Laboratory Standards Institute (CLSI) M38-A [14]. MICs of antimycotic compounds, alone or in combination, were assessed after $48 \mathrm{~h}$. MFCs of CAS and OG, alone or in combination, were determined following the completion of MIC analysis by spreading entire volumes of microtiter wells $(200 \mu \mathrm{L})$ onto individual potato dextrose agar (PDA) recovery plates and culturing for an additional $48 \mathrm{~h}$. Compound interactions, namely fractional inhibitory concentration indices (FICIs) and fractional fungicidal concentration indices (FFCI) for determining CAS + OG synergism for "growth inhibitory" and "fungal death", respectively, were calculated as follows: FICI or FFCI = $(\mathrm{MIC}$ or MFC of Compound A in combination with Compound B/MIC or MFC of Compound A, alone) + (MIC or MFC of Compound B in combination with Compound A/MIC or MFC of Compound B, alone). Levels and types of compound interactions between antimycotic agents were defined as: synergistic (FICI or FFCI $\leq 0.5$ ) or indifferent (FICI or FFCI > 0.5-4) [15]. If preferred, Isenberg's [16] methodology could be substituted in parallel determinations of synergism, where compound interactions were: synergistic $(\mathrm{FICI} \leq 0.5)$, additive $(0.5<\mathrm{FICI} \leq 1)$, neutral $(1<\mathrm{FICI} \leq 2)$ or antagonistic $(\mathrm{FICI}>2)$.

\subsection{Statistical Analysis}

Statistical analysis (Student's $t$-test) was performed according to "Statistics to use" [17], where $p<0.05$ was considered significant.

\section{Results and Discussion}

\subsection{Octyl Gallate Perturbs the Fungal Cell Wall Integrity System: S. cerevisiae Bioassay}

To determine whether OG could target the cell wall integrity system of fungi, OG susceptibility of eleven mutants of the model yeast $S$. cerevisiae, where genes in the cell wall integrity mitogen-activated protein kinase (MAPK) pathway were systematically deleted (Figure 1, Table S1), was initially examined. S. cerevisiae is a useful model system for identifying antifungal agents and their gene targets in that: (1) many genes in S. cerevisiae are orthologs of genes of fungal pathogens [18]; and (2) S. cerevisiae gene deletion mutant collections have proven to be very useful for genome-wide drug-induced haploinsufficiency screens to determine drug's mode of action [19-21]. OG is a generally recognized as safe (GRAS) reagent [22] and, thus, is currently used as an antioxidant added to food. OG is also known to inhibit the growth of bacterial pathogens, such as Staphylococcus aureus [23] and dairy isolates of Enterococcus faecalis expressing different virulence factors [24].

Results showed that $b c k 1 \Delta$ (MAPK kinase kinase (MAPKKK) mutant) and slt2 $\Delta$ (MAPK mutant) were the most sensitive mutants to OG (viz., both MICs and MFCs = $25 \mu \mathrm{M}$; mean MICs and MFCs for other yeast strains $=47$ and $50 \mu \mathrm{M}$, respectively; table data not shown). We further observed that CAS + OG chemosensitization could lower dosages of CAS and OG to achieve $\geq 99.9 \%$ fungal death, where slt2 $\Delta$ required much smaller dosages of each reagent (CAS: $0.25 \mu \mathrm{g} / \mathrm{mL}$; OG: $12.5 \mu \mathrm{M}$ ), when compared to the wild type (CAS: $2.00 \mu \mathrm{g} / \mathrm{mL}$; OG: $25.0 \mu \mathrm{M}$ ) (Figure 2).

The $b c k 1 \Delta$ and slt2 $\Delta$ previously exhibited hypersensitivity to cell wall-perturbing agents including CAS [25] and, therefore, have been serving as screening tools for identifying new cell wall disrupting drugs [25]. Thus, hypersensitive response of $b c k 1 \Delta$ and slt $2 \Delta$ to OG indicates that OG could target the fungal cell wall system. 


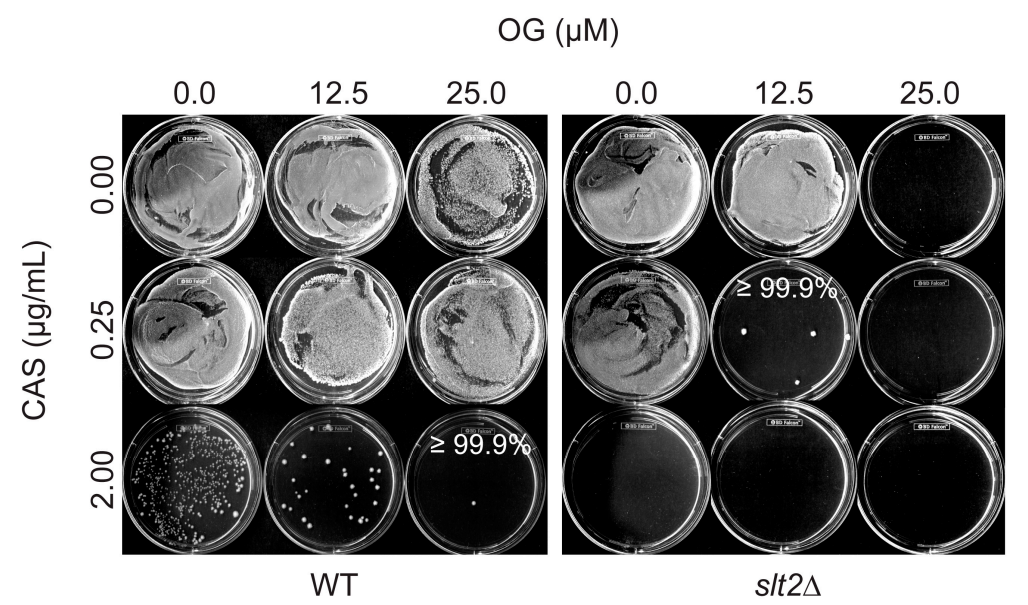

Figure 2. Exemplary chemosensitization (CAS + OG) test in S. cerevisiae wild type (WT) and slt2 $\Delta$ strains. Results shown here are the determination of minimum fungicidal concentrations (MFCs), after MIC measurement in 96-well microplates, of antifungal agents ( $\geq 99.9 \%$ indicates achievement of $\geq 99.9 \%$ fungal death). Note that slt $2 \Delta$ required much lower dosages of CAS and OG to achieve $\geq 99.9 \%$ fungal death, when compared to the WT (see the text).

\subsection{Octyl Gallate Enhances the Efficacy of Caspofungin: Filamentous Fungi Bioassay}

Antifungal chemosensitization (CAS + OG) was then investigated in filamentous fungal pathogens (Aspergillus, Penicillium). For FICIs in Aspergillus, "synergistic" FICI values (i.e., FICI $\leq 0.5$ ) were found between OG and CAS for A. flavus 3357 and A. parasiticus 2999 (Table 2). Although there was no calculated synergism, as determined by "indifferent" [15] or "additive" interactions [16], there was enhanced antifungal activity of OG and CAS also in other Aspergillus strains, which was reflected in lowered MICs of OG or CAS (FICIs = 0.6 to 1.0) when two compounds were co-applied (Table 2). Of note, "synergistic" FICI values (FICI $\leq 0.5)$ were determined for most Penicillium strains tested (FICIs $=0.3$ to 0.5 ). The only exception was P. griseofulvum 2159, where FICI was 0.6 (Table 2). Therefore, the results indicated that Penicillium species were more susceptible to OG-mediated chemosensitization than the Aspergillus strains examined.

Table 2. Antifungal chemosensitization of octyl gallate (OG; $\mathrm{mM})$ to caspofungin $(\mathrm{CAS} ; \mu \mathrm{g} / \mathrm{mL})$ tested against filamentous fungi. Synergistic fractional inhibitory concentration indices (FICIs) and fractional fungicidal concentration indices $(\mathrm{FFCI})(\leq 0.5)$ are shown in bold characters. ${ }^{1}$.

\begin{tabular}{|c|c|c|c|c|c|c|c|}
\hline Strains & Compounds & $\begin{array}{c}\text { MIC } \\
\text { Alone }\end{array}$ & $\begin{array}{c}\text { MIC } \\
\text { Combined }\end{array}$ & FICI & $\begin{array}{l}\text { MFC } \\
\text { Alone }\end{array}$ & $\begin{array}{c}\text { MFC } \\
\text { Combined }\end{array}$ & FFCI \\
\hline \multirow{2}{*}{ A. fumigatus AF293 } & CAS & 128 & 32 & \multirow{2}{*}{0.8} & 128 & 64 & \multirow{2}{*}{1.0} \\
\hline & OG & 0.2 & 0.1 & & 0.4 & 0.2 & \\
\hline \multirow{2}{*}{ A. fumigatus sakA $\triangle$} & CAS & 128 & 8 & \multirow{2}{*}{0.6} & 128 & 64 & \multirow{2}{*}{1.0} \\
\hline & OG & 0.2 & 0.1 & & 0.2 & 0.1 & \\
\hline \multirow{2}{*}{ A. fumigatus mpkCD } & CAS & 128 & 8 & \multirow{2}{*}{0.6} & 128 & 64 & \multirow{2}{*}{0.8} \\
\hline & OG & 0.2 & 0.1 & & 0.4 & 0.1 & \\
\hline \multirow{2}{*}{ A. flavus 4212} & CAS & 128 & 64 & \multirow{2}{*}{1.0} & 128 & 64 & \multirow{2}{*}{1.0} \\
\hline & OG & 0.2 & 0.1 & & 0.4 & 0.2 & \\
\hline \multirow{2}{*}{ A. flavus 3357} & CAS & 128 & 2 & \multirow{2}{*}{0.5} & 128 & 128 & \multirow{2}{*}{2.0} \\
\hline & OG & 0.4 & 0.2 & & 1.6 & 1.6 & \\
\hline \multirow{2}{*}{ A. parasiticus 5862} & CAS & 128 & 64 & \multirow{2}{*}{1.0} & 128 & 128 & \multirow{2}{*}{2.0} \\
\hline & OG & 0.4 & 0.2 & & 1.6 & 1.6 & \\
\hline \multirow{2}{*}{ A. parasiticus 2999} & CAS & 128 & 4 & \multirow{2}{*}{0.5} & 128 & 64 & \multirow{2}{*}{0.6} \\
\hline & OG & 0.4 & 0.2 & & 1.6 & 0.2 & \\
\hline
\end{tabular}


Table 2. Cont.

\begin{tabular}{|c|c|c|c|c|c|c|c|}
\hline Strains & Compounds & $\begin{array}{c}\text { MIC } \\
\text { Alone }\end{array}$ & $\begin{array}{c}\text { MIC } \\
\text { Combined }\end{array}$ & FICI & $\begin{array}{c}\text { MFC } \\
\text { Alone }\end{array}$ & $\begin{array}{c}\text { MFC } \\
\text { Combined }\end{array}$ & FFCI \\
\hline \multirow{2}{*}{ Mean, Aspergillus ${ }^{2}$} & CAS & 128.00 & 33.20 & \multirow{2}{*}{0.8} & 128.00 & 89.60 & \multirow{2}{*}{1.4} \\
\hline & OG & 0.32 & 0.16 & & 1.12 & 0.76 & \\
\hline \multirow{2}{*}{$t$-test ${ }^{3}$} & CAS & - & $p<0.001$ & \multirow[b]{2}{*}{-} & - & $p<0.05$ & \multirow{2}{*}{-} \\
\hline & OG & - & $p<0.05$ & & - & $p<0.5$ & \\
\hline \multirow{2}{*}{ P. expansum W1 } & CAS & 128 & 32 & \multirow{2}{*}{0.5} & 128 & $32^{4}$ & \multirow{2}{*}{0.8} \\
\hline & OG & 0.2 & 0.05 & & 1.6 & 0.8 & \\
\hline \multirow{2}{*}{ P. expansum FR2 } & CAS & 128 & 32 & \multirow{2}{*}{0.5} & 128 & 32 & \multirow{2}{*}{0.8} \\
\hline & OG & 0.2 & 0.05 & & 1.6 & 0.8 & \\
\hline \multirow{2}{*}{ P. expansum W2 } & CAS & 128 & 32 & \multirow{2}{*}{0.5} & 128 & 32 & \multirow{2}{*}{0.8} \\
\hline & OG & 0.2 & 0.05 & & 1.6 & 0.8 & \\
\hline \multirow{2}{*}{ P. expansum FR3 } & CAS & 128 & 32 & \multirow{2}{*}{0.5} & 128 & 32 & \multirow{2}{*}{0.8} \\
\hline & OG & 0.2 & 0.05 & & 1.6 & 0.8 & \\
\hline \multirow{2}{*}{ P. glabrum 766} & CAS & 128 & 16 & \multirow{2}{*}{0.3} & 128 & 32 & \multirow{2}{*}{0.3} \\
\hline & OG & 0.2 & 0.025 & & 1.6 & 0.05 & \\
\hline \multirow{2}{*}{ P. italicum 983} & CAS & 64 & 16 & \multirow{2}{*}{0.5} & 64 & 16 & \multirow{2}{*}{0.8} \\
\hline & OG & 0.2 & 0.05 & & 0.4 & 0.2 & \\
\hline \multirow{2}{*}{ P. griseofulvum 2159} & CAS & 128 & 8 & \multirow{2}{*}{0.6} & 128 & 16 & \multirow{2}{*}{0.4} \\
\hline & OG & 0.2 & 0.1 & & 0.8 & 0.2 & \\
\hline \multirow{2}{*}{ P. chrysogenum 824} & CAS & 128 & 16 & \multirow{2}{*}{0.4} & 128 & 32 & \multirow{2}{*}{0.5} \\
\hline & OG & 0.2 & 0.05 & & 0.2 & 0.05 & \\
\hline \multirow{2}{*}{ Mean, Penicillium ${ }^{2}$} & CAS & 117.33 & 20.00 & O & 117.33 & 26.67 & 06 \\
\hline & OG & 0.20 & 0.05 & 0.4 & 1.03 & 0.35 & 0.6 \\
\hline$+\operatorname{tec} 3$ & CAS & - & $p<0.001$ & & - & $p=0.05$ & \\
\hline$t$-test ${ }^{3}$ & OG & - & $p<0.001$ & - & - & $p<0.05$ & - \\
\hline Moาn TOTAI 2 & CAS & 122.18 & 26.00 & & 122.18 & 55.27 & \\
\hline Mean, TOTAL ${ }^{2}$ & OG & 0.25 & 0.10 & 0.6 & 1.07 & 0.54 & 1.0 \\
\hline 3 & CAS & - & $p<0.001$ & 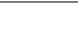 & - & $p<0.001$ & 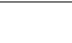 \\
\hline$t$-test & OG & - & $p<0.001$ & - & - & $p<0.05$ & - \\
\hline
\end{tabular}

1 OG was tested at $0.0125,0.025,0.05,0.1,0.2,0.4,0.8 \mathrm{mM}$, while CAS was examined at $0.0625,0.125,0.25,0.5,1,2$, $4,8,16,32 \mu \mathrm{g} / \mathrm{mL} ;{ }^{2}$ mean values were calculated by excluding mutant strains (sakA $\Delta, m p k C \Delta$, FR2, FR3); ${ }^{3} t$-test, Student's $t$-test for paired data (combined; chemosensitization) vs. mean MIC or MFC of each compound (alone; no chemosensitization) determined in strains; statistical analysis was performed according to "Statistics to use" [17], where $p<0.05$ was considered significant; ${ }^{4}$ achievement of $99.5 \%$ fungal death.

Regarding FFCIs in Aspergillus, enhanced fungicidality of CAS or OG was identified during chemosensitization (FFCIs $=0.6-1.0$; additive [16]), despite no calculated synergism. For example, co-application of OG $(0.1,0.1$ or $0.2 \mathrm{mM}$ for $s a k A \Delta, m p k C \Delta$ or wild type, respectively) with CAS $(64 \mu \mathrm{g} / \mathrm{mL})$ achieved $\geq 99.9 \%$ fungal death of $A$. fumigatus, while individual treatment of each compound, alone, at the same concentrations allowed the survival of A. fumigatus. Of note, sakA $\triangle$ and $m p k C \Delta$ (antioxidant signaling mutants) $[10,11]$ were more susceptible to the chemosensitizer, viz. they required a lower concentration of OG compared to the wild type (Table 2; Figure 3). However, the enhanced level of OG on CAS lethality was not high against these mutants when their MFC values were compared to that of the wild type, indicating that the chemosensitizing capability of OG was at the level of lowering MICs (but not MFCs, thus fungistatic, but not fungicidal) in sakA $\triangle$ and mpkC $\Delta$. Meanwhile, no enhancement in fungicidality was identified in A. flavus 3357 and A. parasiticus 5862 during chemosensitization, even at the highest concentrations of either compound applied (FFCI $=2.0$ ).

Synergistic FFCIs were also identified in P. glabrum 766, P. griseofulvum 2159 and P. chrysogenum 824 (FFCIs $=0.3$ to 0.5 ) (Table 2; see also Figure S1). Although no calculated synergism was determined, there was enhanced antifungal activity of CAS and OG for the remaining Penicillium strains (FFCIs = 0.8; additive [16]) during chemosensitization. P. glabrum 766 and P. chrysogenum 824 were the most susceptible strains to the chemosensitization, where synergism was found for both 
FICIs and FFCIs (Table 2; Figure S1). In general, Penicillium strains were more susceptible to CAS (viz., required lower concentration of CAS; 16-32 $\mu \mathrm{g} / \mathrm{mL}$ ) during chemosensitization, when compared to the Aspergillus strains (64-128 $\mathrm{gg} / \mathrm{mL}$ CAS) (Table 2; Figure S1). The differences in susceptibility between Penicillium and Aspergillus to chemosensitization may be due to differences in cell wall sugar composition, such as mannose, galactose, galactofuranose, etc. [26,27]. Elucidation of the precise mechanism of differential susceptibility of fungi to chemosensitization warrants future in-depth investigation.

In the previous acute toxicity tests, the $\mathrm{LD}_{50}$ values of $\mathrm{OG}$ in rat had been determined as 1960-2710 mg/ kg body weight [28], while no observed adverse effect of OG was identified at $50 \mathrm{mg} / \mathrm{kg}$ body weight/day in a reproductive toxicity study [29]. Therefore, the mean MFCs for OG, viz. $0.76 \mathrm{mM}$ $(0.215 \mathrm{mg} / \mathrm{mL})$ or $0.35 \mathrm{mM}(0.099 \mathrm{mg} / \mathrm{mL})$, applied to achieve $\geq 99.9 \%$ fungal death in Aspergillus or Penicillium, respectively, are considered safe (See Table 2).

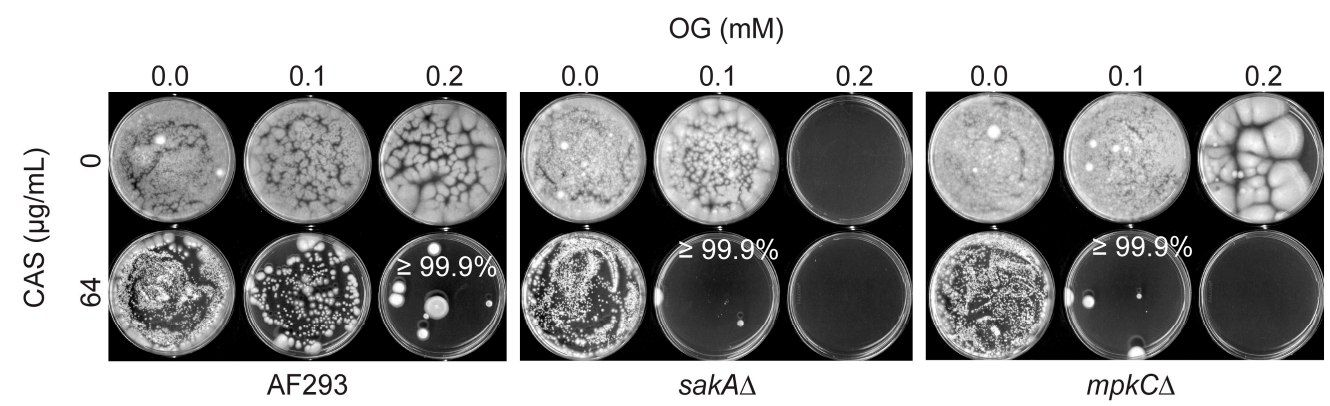

Figure 3. Chemosensitization test in A. fumigatus wild type (AF293), sakA $\Delta$ and $m p k C \Delta$. Results shown here are the determination of MFCs of antifungal agents (CAS, OG) $(\geq 99.9 \%$ indicates achievement of $\geq 99.9 \%$ of fungal death).

\subsection{Octyl Gallate Debilitates Antioxidant Mutants during Chemosensitization}

The mode of antifungal action of OG has been discussed in prior studies, where: (i) OG interrupts or disorganizes the lipid bilayer-protein interface in fungal cells [30]; and (ii) OG functions as a pro-oxidant (redox-active oxidative stressor), thus triggering cytotoxicity in fungi [31]. We speculate that, in addition to destabilizing cell wall integrity, disruption of cellular components by the pro-oxidant characteristic of OG could also be one mechanism of action for the enhancement of CAS activity during OG-mediated chemosensitization.

For example, the $A$. fumigatus sak $A \Delta$ and $m p k C \Delta$ antioxidant mutants were more susceptible to chemosensitization (OG + CAS) compared to the wild type (see above). Redox-active compounds, such as benzo derivatives or sulfur-containing compounds, could function as potent redox-cyclers in microbes and, thus, inhibit pathogen growth by interfering with cellular antioxidant systems, redox homeostasis or the function of redox-sensitive macromolecules [32,33]. Therefore, it is postulated that, in addition to destabilizing the cell wall integrity system, the redox-active OG (chemosensitizer) can further debilitate the susceptibility, viz. defects in ameliorating oxidative stress and/or disruption of cellular redox homeostasis, of the antioxidant mutants during chemosensitization. From the pathogens' perspective, an intact antioxidant signaling system, such as the MAPK pathway, plays an important role in fungal defense against the OG-mediated chemosensitization.

Notably, previous studies showed that, in addition to the cell wall integrity system, another signaling pathway, viz. the "antioxidant" MAPK system, also plays an important role in fungal susceptibility to cell wall-interfering agents (see below). In principle, a functionally-intact antioxidant MAPK system is required for achieving the fungicidal effects of cell wall-disrupting drugs, while mutations in the system result in resistance to the drugs. For instance, the antioxidant MAPK pathway mutants of $S$. cerevisiae, such as hog1 (MAPK) or pbs2 (MAPK kinase; MAPKK) mutants, exhibited tolerance to cell wall-interfering agents [34-36]. A similar type of drug tolerance was also 
observed in Candida albicans [37]. Fungal dialogs between "antioxidant" and "cell wall integrity" MAPK pathways have been well documented recently [38]. Identification of the precise mechanism or cellular target(s) of OG during chemosensitization warrants future study.

\section{Conclusions}

In conclusion, chemosensitization could be an effective antifungal intervention strategy (see also [39]). OG, a safe, alkyl derivative of natural benzoate, possesses the potential to serve as an antimycotic chemosensitizer when co-applied with CAS. This potential appears to be greatest with Penicillium strains. OG-mediated chemosensitization, as presented here, can sensitize cell wall integrity and antioxidant systems of filamentous fungi and, thus, can lower effective doses of toxic antifungal agents (such as CAS), leading to coincidental lowering of environmental and health risks. The use of safe chemosensitizers as intervention catalysts that debilitate filamentous fungal pathogens could be a viable approach for pathogen control. Inclusion of more clinical strains, such as A. fumigatus, A. terreus, A. niger, etc., in future tests would be necessary. There could be significant differences in efficacy for different strains of the same species. Future in vivo studies are also necessary to determine potential applications of chemosensitization in therapeutic settings.

Supplementary Materials: The following are available online at http:/ /www.mdpi.com/2571-8800/1/1/4/s1, Figure S1: Chemosensitization test in A. flavus 4212, A. parasiticus 2999, P. italicum 983 and P. glabrum 766; Table S1: The model yeast Saccharomyces cerevisiae strains used in this study.

Author Contributions: J.H.K. conceived of, designed and performed the research including data analysis and interpretation and the literature search and wrote the manuscript. K.L.C. performed the antifungal bioassays and prepared the figures. L.W.C., Research Leader, directed the research.

Acknowledgments: This research was conducted under USDA-ARS CRIS Project 5325-42000-039-00D.

Conflicts of Interest: The authors declare no conflict of interest.

\section{References}

1. McCarthy, M.W.; Kontoyiannis, D.P.; Cornely, O.A.; Perfect, J.R.; Walsh, T.J. Novel agents and drug targets to meet the challenges of resistant fungi. J. Infect. Dis. 2017, 216, S474-S483. [CrossRef] [PubMed]

2. Beauvais, A.; Latgé, J.P. Membrane and cell wall targets in Aspergillus fumigatus. Drug Resist. Updates 2001, 4, 38-49. [CrossRef] [PubMed]

3. Fuchs, B.B.; Mylonakis, E. Our paths might cross: The role of the fungal cell wall integrity pathway in stress response and cross talk with other stress response pathways. Eukaryot. Cell 2009, 8, 1616-1625. [CrossRef] [PubMed]

4. Fujioka, T.; Mizutani, O.; Furukawa, K.; Sato, N.; Yoshimi, A.; Yamagata, Y.; Nakajima, T.; Abe, K. MpkA-Dependent and -independent cell wall integrity signaling in Aspergillus nidulans. Eukaryot. Cell 2007, 6, 1497-1510. [CrossRef] [PubMed]

5. Perlin, D.S. Mechanisms of echinocandin antifungal drug resistance. Ann. N. Y. Acad. Sci. 2015, 1354, 1-11. [CrossRef] [PubMed]

6. Walker, L.A.; Lee, K.K.; Munro, C.A.; Gow, N.A. Caspofungin treatment of Aspergillus fumigatus results in ChsG-dependent upregulation of chitin synthesis and the formation of chitin-rich micro-colonies. Antimicrob. Agents Chemother. 2015, 59, 5932-5941. [CrossRef] [PubMed]

7. Cowen, L.E.; Steinbach, W.J. Stress, drugs, and evolution: The role of cellular signaling in fungal drug resistance. Eukaryot. Cell 2008, 7, 747-764. [CrossRef] [PubMed]

8. Campbell, B.C.; Chan, K.L.; Kim, J.H. Chemosensitization as a means to augment commercial antifungal agents. Front. Microbiol. 2012, 3, 79. [CrossRef] [PubMed]

9. Buckley, H.L.; Hart-Cooper, W.M.; Kim, J.H.; Faulkner, D.M.; Cheng, L.W.; Chan, K.L.; Vulpe, C.D.; Orts, W.J.; Amrose, S.E.; Mulvihill, M.J. Design and testing of safer, more effective preservatives for consumer products. ACS Sustain. Chem. Eng. 2017, 5, 4320-4331. [CrossRef]

10. Xue, T.; Nguyen, C.K.; Romans, A.; May, G.S. A mitogen-activated protein kinase that senses nitrogen regulates conidial germination and growth in Aspergillus fumigatus. Eukaryot. Cell 2004, 3, 557-560. [CrossRef] [PubMed] 
11. Reyes, G.; Romans, A.; Nguyen, C.K.; May, G.S. Novel mitogen-activated protein kinase MpkC of Aspergillus fumigatus is required for utilization of polyalcohol sugars. Eukaryot. Cell 2006, 5, 1934-1940. [CrossRef] [PubMed]

12. Li, H.X.; Xiao, C.L. Characterization of fludioxonil-resistant and pyrimethanil-resistant phenotypes of Penicillium expansum from apple. Phytopathology 2008, 98, 427-435. [CrossRef] [PubMed]

13. Arendrup, M.C.; Cuenca-Estrella, M.; Lass-Flörl, C.; Hope, W. EUCAST technical note on the EUCAST definitive document EDef 7.2: Method for the determination of broth dilution minimum inhibitory concentrations of antifungal agents for yeasts EDef 7.2 (EUCAST-AFST). Clin. Microbiol. Infect. 2012, 18, E246-E247. [CrossRef] [PubMed]

14. Clinical and Laboratory Standards Institute (CLSI). Reference Method for Broth Dilution Antifungal Susceptibility Testing of Filamentous Fungi: Approved Standard, 2nd ed.; CLSI Document M38-A2; Clinical and Laboratory Standards Institute: Wayne, PA, USA, 2008; Volume 28.

15. Odds, F.C. Synergy, antagonism, and what the chequerboard puts between them. J. Antimicrob. Chemother. 2003, 52, 1. [CrossRef] [PubMed]

16. Isenberg, H.D. Clinical Microbiology Procedures Handbook, 1st ed.; American Society for Microbiology: Washington, DC, USA, 1992.

17. Kirkman, T.W. Statistics to Use. Available online: http://www.physics.csbsju.edu/stats/ (accessed on 23 April 2018).

18. Kim, J.H.; Campbell, B.C.; Yu, J.; Mahoney, N.; Chan, K.L.; Molyneux, R.J.; Bhatnagar, D.; Cleveland, T.E. Examination of fungal stress response genes using Saccharomyces cerevisiae as a model system: Targeting genes affecting aflatoxin biosynthesis by Aspergillus flavus Link. Appl. Microbiol. Biotechnol. 2005, 67, 807-815. [CrossRef] [PubMed]

19. Lee, A.Y.; St.Onge, R.P.; Proctor, M.J.; Wallace, I.M.; Nile, A.H.; Spagnuolo, P.A.; Jitkova, Y.; Gronda, M.; $\mathrm{Wu}, \mathrm{Y}$;; Kim, M.K.; et al. Mapping the cellular response to small molecules using chemogenomic fitness signatures. Science 2014, 344, 208-211. [CrossRef] [PubMed]

20. Norris, M.; Lovell, S.; Delneri, D. Characterization and prediction of haploinsufficiency using systems-level gene properties in yeast. G3 2013, 3, 1965-1977. [CrossRef] [PubMed]

21. Parsons, A.B.; Brost, R.L.; Ding, H.; Li, Z.; Zhang, C.; Sheikh, B.; Brown, G.W.; Kane, P.M.; Hughes, T.R.; Boone, $\mathrm{C}$. Integration of chemical-genetic and genetic interaction data links bioactive compounds to cellular target pathways. Nat. Biotechnol. 2003, 22, 62. [CrossRef] [PubMed]

22. U.S. Food and Drug Administration (FDA). Everything Added to Food in the United States. 2011. Available online: http:/ / www.fda.gov/Food/IngredientsPackagingLabeling/FoodAdditivesIngredients/ucm115326. htm (accessed on 23 April 2018).

23. Rúa, J.; Fernandez-Álvarez, L.; de Castro, C.; del Valle, P.; de Arriaga, D.; Garcia-Armesto, M.R. Antibacterial activity against foodborne Staphylococcus aureus and antioxidant capacity of various pure phenolic compounds. Foodborne Pathog. Dis. 2011, 8, 149-157. [CrossRef] [PubMed]

24. Gutiérrez-Fernández, J.; García-Armesto, M.R.; Álvarez-Alonso, R.; del Valle, P.; de Arriaga, D.; Rúa, J. Antimicrobial activity of binary combinations of natural and synthetic phenolic antioxidants against Enterococcus faecalis. J. Dairy Sci. 2013, 96, 4912-4920. [CrossRef] [PubMed]

25. Reinoso-Martín, C.; Schüller, C.; Schuetzer-Muehlbauer, M.; Kuchler, K. The yeast protein kinase C cell integrity pathway mediates tolerance to the antifungal drug caspofungin through activation of Slt2p mitogen-activated protein kinase signaling. Eukaryot. Cell 2003, 2, 1200-1210. [CrossRef] [PubMed]

26. Parra, E.; Jiménez-Barbero, J.; Bernabe, M.; Leal, J.A.; Prieto, A.; Gómez-Miranda, B. Structural investigation of two cell-wall polysaccharides of Penicillium expansum strains. Carbohydr. Res. 1994, 257, 239-248. [CrossRef]

27. Gow, N.A.R.; Latge, J.-P.; Munro, C.A. The fungal cell wall: Structure, biosynthesis, and function. Microbiol. Spectr. 2017, 5. [CrossRef] [PubMed]

28. Joint FAO/WHO Expert Committee on Food Additives. Evaluation of the toxicity of a number of antimicrobials and antioxidants. World Health Organ. Tech. Rep. Ser. 1962, 228, 61-65.

29. EFSA ANS Panel (EFSA Panel on Food Additives and Nutrient Sources Added to Food). Scientific Opinion on the re-evaluation of octyl gallate (E 311) as a food additive. EFSA J. 2015, 13, 4248. [CrossRef]

30. Fujita, K.; Kubo, I. Antifungal activity of octyl gallate. Int. J. Food Microbiol. 2002, 79, 193-201. [CrossRef] 
31. Sierra-Campos, E.; Valdez-Solana, M.A.; Matuz-Mares, D.; Velazquez, I.; Pardo, J.P. Induction of morphological changes in Ustilago maydis cells by octyl gallate. Microbiology 2009, 155, 604-611. [CrossRef] [PubMed]

32. Guillen, F.; Evans, C.S. Anisaldehyde and veratraldehyde acting as redox cycling agents for $\mathrm{H}_{2} \mathrm{O}_{2}$ production by Pleurotus eryngii. Appl. Environ. Microbiol. 1994, 60, 2811-2817. [PubMed]

33. Jacob, C. A scent of therapy: Pharmacological implications of natural products containing redox-active sulfur atoms. Nat. Prod. Rep. 2006, 23, 851-863. [CrossRef] [PubMed]

34. García-Rodriguez, L.J.; Durán, A.; Roncero, C. Calcofluor antifungal action depends on chitin and a functional high-osmolarity glycerol response (HOG) pathway: Evidence for a physiological role of the Saccharomyces cerevisiae HOG pathway under noninducing conditions. J. Bacteriol. 2000, 182, 2428-2437. [CrossRef] [PubMed]

35. Jiang, B.; Ram, A.F.; Sheraton, J.; Klis, F.M.; Bussey, H. Regulation of cell wall beta-glucan assembly: PTC1 negatively affects PBS2 action in a pathway that includes modulation of EXG1 transcription. Mol. Gen. Genet. 1995, 248, 260-269. [CrossRef] [PubMed]

36. Lai, M.H.; Silverman, S.J.; Gaughran, J.P.; Kirsch, D.R. Multiple copies of PBS2, MHP1 or LRE1 produce glucanase resistance and other cell wall effects in Saccharomyces cerevisiae. Yeast 1997, 13, 199-213. [CrossRef]

37. Alonso-Monge, R.; Navarro-García, F.; Molero, G.; Diez-Orejas, R.; Gustin, M.; Pla, J.; Sánchez, M.; Nombela, C. Role of the mitogen-activated protein kinase Hog1p in morphogenesis and virulence of Candida albicans. J. Bacteriol. 1999, 181, 3058-3068. [PubMed]

38. Rodríguez-Peña, J.M.; García, R.; Nombela, C.; Arroyo, J. The high-osmolarity glycerol (HOG) and cell wall integrity (CWI) signalling pathways interplay: A yeast dialogue between MAPK routes. Yeast 2010, 27, 495-502. [CrossRef] [PubMed]

39. Ogita, A.; Fujita, K.; Taniguchi, M.; Tanaka, T. Enhancement of the fungicidal activity of amphotericin B by allicin, an allyl-sulfur compound from garlic, against the yeast Saccharomyces cerevisiae as a model system. Planta Med. 2006, 72, 1247-1250. [CrossRef] [PubMed]

(C) 2018 by the authors. Licensee MDPI, Basel, Switzerland. This article is an open access article distributed under the terms and conditions of the Creative Commons Attribution (CC BY) license (http://creativecommons.org/licenses/by/4.0/). 